\title{
Performance of Quantitative Vegetation Sampling Methods Across Gradients of Cover in Great Basin Plant Communities
}

\author{
David S. Pilliod ${ }^{1}$ and Robert S. Arkle ${ }^{2}$ \\ Authors are ${ }^{1}$ Supervisory Research Ecologist and ${ }^{2}$ Supervisory Ecologist, US Geological Survey, Forest and Rangeland Ecosystem Science Center, Snake \\ River Field Station, Boise, Idaho 83706, USA.
}

\begin{abstract}
Resource managers and scientists need efficient, reliable methods for quantifying vegetation to conduct basic research, evaluate land management actions, and monitor trends in habitat conditions. We examined three methods for quantifying vegetation in 1-ha plots among different plant communities in the northern Great Basin: photography-based grid-point intercept (GPI), linepoint intercept (LPI), and point-quarter (PQ). We also evaluated each method for within-plot subsampling adequacy and effort requirements relative to information gain. We found that, for most functional groups, percent cover measurements collected with the use of LPI, GPI, and PQ methods were strongly correlated. These correlations were even stronger when we used data from the upper canopy only (i.e., top "hit" of pin flags) in LPI to estimate cover. PQ was best at quantifying cover of sparse plants such as shrubs in early successional habitats. As cover of a given functional group decreased within plots, the variance of the cover estimate increased substantially, which required more subsamples per plot (i.e., transect lines, quadrats) to achieve reliable precision. For GPI, we found that that six-nine quadrats per hectare were sufficient to characterize the vegetation in most of the plant communities sampled. All three methods reasonably characterized the vegetation in our plots, and each has advantages depending on characteristics of the vegetation, such as cover or heterogeneity, study goals, precision of measurements required, and efficiency needed.
\end{abstract}

Key Words: canopy cover, field methods, protocols, sagebrush-steppe, salt desert scrub

\section{INTRODUCTION}

Monitoring natural and anthropogenic changes in shrubland ecosystems is a high priority for researchers and resource managers engaged in restoration and adaptive management. The northern Great Basin has experienced widespread conversion of native shrublands to invasive annual grasslands or juniper (Juniperus occidentalis) woodlands as a result of altered fire regimes and other processes (Knapp 1996). Scientists and resource managers are attempting to understand and reverse this trend by manipulating existing vegetation, seeding, and monitoring (Briske et al. 2005; Allcock et al. 2006; EpanchinNiell et al. 2009). Many sampling methods have been developed and used to describe shrubland and grassland communities (e.g., Elzinga et al. 2001; Herrick et al. 2005; Seefeldt and Booth 2006). Most methodologies attempt to quantify native plant diversity, exotic species distribution, rare plant occurrence, seeded species establishment, and vegetation cover efficiently. These metrics are generally viewed as important indicators of rangeland conditions associated with grazing, erosion potential, wildlife habitat quality, resistance of habitats to exotic species invasion and state transitions, and

Research was funded by the US Geological Survey Coordinated Sagebrush Studies Program.

Correspondence: David S. Pilliod, US Geological Survey, Forest and Rangeland Ecosystem Science Center, Snake River Field Station, 970 Lusk Street, Boise, ID 83706, USA. Email: dpilliod@usgs.gov

Manuscript received 30 April 2013; manuscript accepted 2 September 2013.

(c) 2013 The Society for Range Management resilience to changing climates and grazing practices (Pyke et al. 2002; Herrick et al. 2012).

In the last decade, rangeland managers and scientists in the western United States have collaborated to standardize shrubland vegetation monitoring to produce statistically defensible information and to compile comparable data across diverse locations (e.g., Wirth and Pyke 2007; Herrick et al. 2010). Acquiring standardized, defensible data requires a shift from ocular estimates, qualitative data, and convenience samples to inferential, quantitative sampling that accounts for natural heterogeneity across landscapes of interest. As rangeland sampling and monitoring has moved in this direction, many studies have compared traditional ocular techniques to more quantitative methods for estimating cover and composition of rangeland vegetation (e.g., Hanley 1978; Floyd and Anderson 1987; Seefeldt and Booth 2006; Godinez-Alvarez et al. 2009). Most quantitative methods, such as point- and line-intercept sampling approaches, have been shown to provide greater accuracy, precision, and repeatability than ocular estimators. Fewer studies have examined the conditions under which a particular quantitative method is optimal given variability in plant cover, rarity of target species, precision needed to detect change over time or space with confidence, and the effort and cost associated with each. This information is particularly needed, as the demand for better assessments of rangeland conditions and restoration effectiveness has increased, while financial resources for monitoring remain limited.

The challenge of sampling shrubland communities is predominantly spatial heterogeneity or patchiness of vegetation, an issue recognized as far back as the 1940s (Pehanec and Stewart 1941; Daubenmire 1959). Successful characterization 
of heterogeneous landscapes and study plots requires thoughtful experimental design and careful selection of field methods best suited to proposed objectives and vegetation conditions. The number and spatial distribution of plots (i.e., sample units) throughout the landscape of interest should be sufficient to characterize vegetation (i.e., central tendency and variation) along gradients of interest, such as cover (Huenneke et al. 2001). The size and shape of plots have well-documented effects on sampling results, and these plot attributes may depend upon the spatial scale at which vegetation varies in a given landscape or the objective of the sampling (Pehanec and Stewart 1940). Most plots larger than a few square meters require subsampling, such as with multiple transects or quadrats. These subsamples are usually averaged together to characterize the plot. Thus, the type (e.g., linear vs. area based) and configuration (e.g., random or systematic) of subsample units is of critical importance for addressing study objectives and for quantifying vegetation heterogeneity within study plots (Daubenmire 1959). The number of subsamples needed depends upon the abundance and compositional or structural variability of vegetation within a plot (Inouye 2002). Variability among subsamples within a given plot can provide valuable information regarding spatial heterogeneity of vegetation. This information could be useful for examining plant-plant interactions, animal habitat quality, or remote sensing error rates.

Point-intercept methods are commonly used to quantify vegetation, fuel, and soil characteristics in shrubland and grassland ecosystems. Line-point intercept (LPI) is a variation of the point-intercept method, where sample points are arranged, usually systematically, along a line transect that extends tens of meters (30-70 m are commonly used; Elzinga et al. 2001). Cover is measured as the number of times a point projected vertically from above (usually with a pin flag, laser, or optical sighting device) contacts or "hits" a target object (e.g., litter, rock, plant species) divided by the total number of points measured along the line. Oftentimes, multiple lines are sampled in a given plot, and these subsamples are summed or can be averaged to provide an estimate of central tendency and variance for the cover of objects, functional groups, or species in the plot. Grid-point intercept (GPI) is similar to LPI, except that sample points are arranged in a systematic, twodimensional grid of a given size (e.g., Brun and Box 1963; Floyd and Anderson 1982). For practicality, most GPI grids are created with the use of a quadrat or sampling frame that can be carried easily in the field (e.g., 0.5-1-m sides). GPI measurements of cover are calculated in the same manner as LPI methods. GPI methods are popular among field biologists because they can be used to produce multiple measures of abundance including cover, density, and frequency (Elzinga et al. 2001). Advances in digital photography and analysis software (Booth et al. 2006a; 2006b) have facilitated the use of photographic methods in GPI that do not require quadrats, frames, or point sampling devices to be carried in the field. Photography-based GPI has the advantage that "reading" the point intercepts can be performed at a later time and by multiple observers because photographs provide a permanent, archivable record of vegetation conditions (Seefeldt and Booth 2006).

The point-centered quarter method $(\mathrm{PQ})$ is more commonly used to measure tree density and cover in forests, but this "plotless" method is useful in shrubland habitats when species or functional groups of interest are rare. This is a common problem for certain forbs, for juniper trees in early successional habitats, and for shrubs and bunchgrasses in restoration areas, particularly after wildfire. For each target species, PQ uses the distance to the nearest individual in each of four quadrants (usually separated by the cardinal directions) to measure relative and absolute density, percent cover, and frequency. Cover estimates derived from PQ measurements assume a random distribution of target species in an area. Thus, plant species that have clumped or uniform distributions may have biased cover estimates with this technique (Engeman et al. 1994).

The goal of this study was to examine cover estimates, precision (within-plot sub-sampling adequacy), and sampling efficiency of LPI, GPI, and PQ vegetation sampling methods in 1-ha plots in upland plant communities in the northern Great Basin. We were particularly interested in how these methods performed across gradients of vegetation cover, community type, and successional state. This analysis was not intended to provide a direct comparison of methods, nor to evaluate the accuracy of methodological measurements relative to truth. Instead, we were interested in examining how these sampling approaches, as typically employed in the field, performed in characterizing vegetation and how performance was influenced by environmental (vegetation) conditions.

\section{METHODS}

\section{Study Area}

We sampled six plant communities in southwestern Idaho and southeastern Oregon (Table 1; Fig. S1, available at http://dx. doi.org/10.2111/REM-D-13-00063.s1). Plots in Idaho had not burned in at least $50 \mathrm{yr}$, whereas plots in Oregon were selected specifically because they were grasslands that resulted from a recent fire in Wyoming big sagebrush, Artemisia tridentata wyomingensis (the Double Mountain Fire in 2005). Burned areas were either left untreated (hereafter Burned) or were seeded (primarily with Pseudoroegneria spicata) with the use of a rangeland drill in fall 2005 (hereafter Treated). These six community types were selected because they represent a wide range of structural complexities (e.g., zero, single, and multiple canopy layers) and they represent the dominant vegetation found in the Great Basin and many other arid rangelands.

Elevations across the study area ranged from 800 to $1900 \mathrm{~m}$ (Table 1). Annual precipitation ranged from $25.8 \mathrm{~cm}$ to 51.2 $\mathrm{cm}$, with higher precipitation at the highest elevations (PRISM data; 1971-2001). Mean annual temperatures ranged from $5.6^{\circ} \mathrm{C}$ to $9.6^{\circ} \mathrm{C}$. Soils included silty loam, sandy loam, and rocky loam. This variation usually coincided with changes in plant community types. All plots were located within Bureau of Land Management sheep and cattle grazing allotments, and we observed consistently light grazing pressure on the study plots in the six plant communities.

\section{Sampling Design}

We sampled 31 1-ha plots in six plant communities (Table 1). The 1-ha plot was our sample unit and was replicated within 
Table 1. Attributes of six Great Basin plant community types sampled (listed in order of elevation). Values given are averaged by 1-ha plots within communities. Precipitation and temperature values are derived from PRISM long-term (1971-2001) raster data. Burned communities were grasslands and Treated communities were seeded grasslands that were sampled 3 yr following a wildfire that burned a Wyoming Big Sagebrush community.

\begin{tabular}{|c|c|c|c|c|c|c|}
\hline Community type & State & Dominant species & $\begin{array}{l}\text { No. of } \\
\text { plots }\end{array}$ & $\begin{array}{l}\text { Elevation } \\
(\mathrm{m})\end{array}$ & $\begin{array}{c}\text { Mean annual } \\
\text { precipitation }(\mathrm{cm})\end{array}$ & $\begin{array}{c}\text { Mean annual } \\
\text { temperature }\left({ }^{\circ} \mathrm{C}\right)\end{array}$ \\
\hline Burned & Oregon & Bromus tectorum or Pseudoroegneria spicata and Poa secunda & 4 & 927 & 29.4 & 9.6 \\
\hline Treated & Oregon & B. tectorum or $P$. spicata and $P$. secunda & 7 & 943 & 29.5 & 9.6 \\
\hline Salt desert scrub & Idaho & $\begin{array}{l}\text { Atriplex canescens, Artemisia tridentata wyomingensis, Grayia } \\
\text { spinosa }\end{array}$ & 5 & 1070 & 25.8 & 9.0 \\
\hline Wyoming big sagebrush & Idaho & A. tridentata wyomingensis & 5 & 1355 & 29.3 & 7.8 \\
\hline Low sagebrush & Idaho & Atriplex arbuscula, and to a lesser extent $A$. tridentata wyomingensis & 5 & 1788 & 46.5 & 5.6 \\
\hline Mountain big sagebrush & Idaho & $\begin{array}{l}\text { Artemisia tridentata vaseyana and to a lesser extent Ericameria } \\
\text { teretifolia, Purshia tridentata }\end{array}$ & 5 & 1857 & 51.2 & 6.0 \\
\hline
\end{tabular}

plant communities. We selected random plot locations within a $1-\mathrm{km}$ buffer of access roads with the use of a geographic information system (GIS). If a plot fell on an ecotone between plant community types, on multiple soil types, or on multiple topographic positions, the plot center was moved a random distance (up to $100 \mathrm{~m}$ ) and direction such that the entire 1-ha plot represented a single ecological site. This avoided confounded effects of plant spatial heterogeneity due to biotic factors (e.g., inter- and intraspecific competition), with effects due to abiotic factors (e.g., soil composition or light availability).

\section{Sampling Methods}

Within each plot, we quantified the vegetation community with the use of all three sampling methods. Field crews were trained

\section{$100 \mathrm{~m}$}

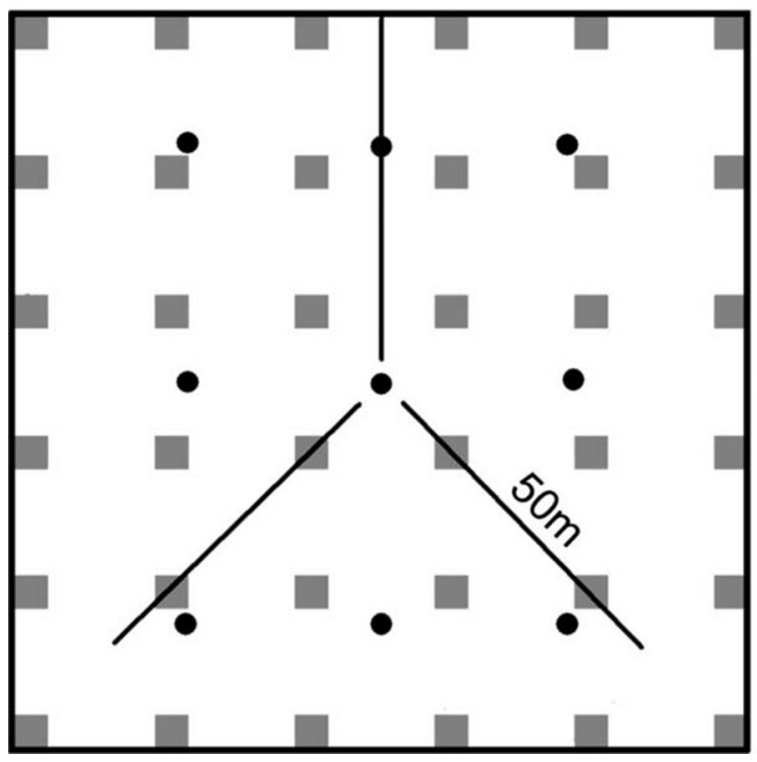

Figure 1. Sampling design used in each 1-ha plot. Lines represent 50-m line-point intercept (LPI) transects. Squares represent $1.5 \times 2 \mathrm{~m}$ grid-point intercept (GPI) quadrats $(n=36)$ collected on a $20-\mathrm{m}$ grid. Circles represent point-centered quarter (PQ) sampling points $(n=9 ; 20-\mathrm{m}$ search radius), collected on a $25-\mathrm{m}$ grid. extensively prior to conducting field work, including calibration of field and photo interpretation methods. The LPI method used a three-spoke design described by Herrick et al. (2005). This approach consists of three 50-m transects radiating out from the plot center at $120^{\circ}$ angles (Fig. 1). Each transect was considered a subsample. Pin flags were dropped vertically from $5 \mathrm{~cm}$ above the vegetation canopy in 1-m increments resulting in 50 pin drops (sample points) per transect. Three transects resulted in 150 sample points per 1-ha plot.

Following each pin drop along a LPI transect, we recorded the plant species and abiotic materials contacting the pin flag sequentially from the upper canopy toward ground level. The base level could be soil, biological crust, or rock, but not litter. Litter, defined as detached dead stems and leaves, was considered a layer above the ground when present. This method provided a multicanopy view of the vegetation and abiotic habitat components of the plot. The multicanopy approach causes percent cover values summed across all objects or species to exceed $100 \%$ sometimes. Based on probabilistic sampling, this method allows users to estimate the percent cover of a given species (or functional group) within a plot, regardless of whether (or how frequently) it occurs in upper or lower canopy levels.

GPI sampling occurred on the same 1-ha plots as LPI. We sampled 36 GPI quadrats per plot, arranged in a $20-\mathrm{m}$ grid pattern that was centered on the plot (Fig. 1). Each quadrat was considered a subsample. We used this systematic sampling approach rather than a random spacing because it provided better coverage of the plot and more closely resembled the systematic sampling of LPI. We used global positioning systems (GPS) to navigate to GPI quadrats within each plot. Within each quadrat, we inventoried all plant species within the photograph footprint and took a nadir photograph. Photographs were taken with Canon PowerShot A590 IS digital cameras (8-megapixel resolution) at nadir (i.e., the area or point on the ground vertically beneath the perspective of the camera lens) from $2 \mathrm{~m}$ above ground level with the use of a monopod $(2 \mathrm{~m}$ tall with a $0.5-\mathrm{m}$ horizontal arm; based on dimensions described in Booth et al. 2004) constructed out of $3 / 4$-in. polyvinyl chloride pipe (Fig. S2, available at http://dx.doi. org/10.2111/REM-D-13-00063.s2). This 2-m camera height corresponded to a $1.5 \times 2 \mathrm{~m}$ area on the ground and provided sufficient height above most shrub species while maintaining a small (about 0.5-1.0 mm, depending on distance of vegetation 
to camera lens) ground sample distance (GSD; the actual linear distance represented by each pixel composing an image).

We used SamplePoint 1.43 software (Booth et al. 2006a) to measure the cover of species and functional groups at 100 computer-selected grid points on each image. The pixel GSD of approximately $0.5-1.0 \mathrm{~mm}$ (a single grid point) was approximately half the diameter of the wire pin flags used for LPI. We measured cover as the percentage of grid points that "hit" a species or abiotic habitat component, which collectively summed to $100 \%$ across each quadrat (i.e., photograph). We referred to the species lists collected in the field at each quadrat only if we were uncertain about a species' identification in the image.

Aboveground photography provides a bird's-eye view of the plot. Therefore, GPI measures cover as the percentage of points within the photograph extent (footprint) where a species or functional group occurs as the uppermost object (i.e., visible from above). However, it is important to note that photography-based GPI does not provide a single-canopy view, at least at the quadrat level. Where plant canopies were absent (e.g., canopy gaps), we could detect litter, biological soil crust, or soil on the ground surface. Therefore, within each quadrat, we were able to measure cover of understory species and litter, and to a lesser extent, soil exposure.

We used the PQ method to quantify the percent cover of relatively rare plants, such as mature native bunchgrasses and shrubs in burned areas and scattered juniper trees. We sampled bunchgrass, shrub, and tree functional groups at nine PQ sampling points in each 1-ha plot (Fig. 1). Each PQ point was considered a subsample of the 1-ha plot. Sampling points were established with the use of a $25-\mathrm{m}$ grid centered on the plot center. At each sample point and for a given target functional group (i.e., bunchgrass, shrub, or tree), we measured the linear distance to the centroid of the nearest individual in four quadrants (NW, NE, SE, and SW) within a 20 -m search radius. We then repeated the process for the two other functional groups. Thus, we measured up to 36 bunchgrass, 36 shrub, and 36 tree individuals per plot if all nine PQ sampling points and their four associated quadrants had qualifying individuals within $20 \mathrm{~m}$. For each qualifying plant, we also measured its diameter (i.e., canopy intercept). Canopy intercept was equal to the distance between the first point of vertical intercept and the last point of vertical intercept through the canopy of an individual plant. To be counted, the canopy intercept was required to be $\geq 15 \mathrm{~cm}$ for a bunchgrass and $\geq 10 \mathrm{~cm}$ for a shrub or tree. If these conditions were not met, the next nearest plant (within the 20-m search radius) meeting the conditions was measured. These size restrictions were imposed to reduce observer bias for large plants and to exclude Poa species, which were generally common enough to be measured using the other methods. If no qualifying plants were present within $20 \mathrm{~m}$, we recorded a distance of $20 \mathrm{~m}$ and a canopy intercept of $0 \mathrm{~cm}$.

\section{Data Analysis}

Percent Cover. With the use of LPI and GPI data, we generated percent cover estimates for each 1-ha plot at two taxonomic resolutions: species and functional groups. We assigned each species or abiotic habitat component to 1 of 10 functional groups on the basis of morphology and life history:
Tree, Shrub, Perennial Grass, Exotic Annual Grass (hereafter Annual Grass), Exotic Forb, Native Forb, Litter (detached plant matter $<5$-mm diameter), Coarse Woody Debris $(\geq 5$ mm diameter), Soil, and Rock ( $\geq 5$-mm minimum diameter).

With the use of LPI data, we quantified percent cover as the number of pin-drop locations (out of 50 possible for each transect line) where a given plant species, or functional group, contacted the pin flag. We then averaged the cover measurements for the three transects within each 1-ha plot. We repeated this process for each plot with the use of only the uppermost species or functional group contacting the pin flag on each pin drop (LPI top canopy hit only). This allowed us to examine the relationship between cover estimates generated by LPI and GPI, because GPI is a view-from-above technique. We also were able to determine how much information about lower canopies was lost as a result of nadir sampling techniques.

To generate percent cover estimates for each 1-ha plot with the use of GPI data, we first divided the number of grid points representing a given species or functional group in an image by the total number of grid points classified per image (usually 100). We then averaged the percent cover values for each species and functional group across the 36 quadrats (photographs) within each 1-ha plot.

With the use of PQ data, we estimated density and percent canopy cover of Tree, Shrub, and Perennial Grass functional groups by averaging nine PQ sample points across each 1-ha plot. The density (number of individuals $\cdot \mathrm{m}^{-2}$ ) of a given functional group was calculated as: $1 /\left(\overline{\mathrm{x}} d_{1}, d_{2}, d_{3}, d_{4}\right)^{2}$ where $d=$ the point-to-plant distance $(\mathrm{m})$ for the closest qualifying plant in each of the four quadrants. This density measurement was used along with canopy intercept data to calculate percent cover at each PQ sample point as: $\left(\overline{\mathrm{x}} a_{1}, a_{2}, a_{3}\right.$, $\left.a_{4}\right) \cdot($ density $) \cdot(100)$, where $a=$ area of plant's canopy; calculated as: $1 / 2 \pi$ (canopy intercept in meters $)^{2}$.

We performed paired regression analyses of each functional group and method. This allowed us to examine percent cover values generated along vegetation and successional gradients, and among plant communities, with the use of the three sampling methods. Each regression had a sample size of 31 plots from six community types. We assessed the correspondence of cover values from different sampling techniques by examining the $r$-squared value $\left(r^{2}\right)$ and slope term ( $\left.\beta\right)$ from each regression analysis. When within-plot cover values from each paired method were strongly associated, $r^{2}$ approached 1 . When there was high within-plot agreement on cover values, a 1:1 relationship existed and $\beta$ approached 1 (this also assumes that the intercept approached zero, which it did). Thus, the overall correspondence of percent cover values from different sampling techniques was greatest when both $r^{2}$ and $\beta=1$. Note that within-plot cover estimates could be strongly associated (high $r^{2}$ ) without providing similar numerical values ( $\beta$ much greater or less than 1 ).

Community Composition. We examined the performance of LPI and GPI methods in quantifying plant community composition with the use of nonmetric multidimensional scaling ordination (NMS; PC-ORD 5.10 software; McCune and Mefford 2006). For this analysis, we treated the GPI data and the LPI data collected on a given plot as separate sample units. Thus, the number of sample units (i.e., plots) in the analysis was 62 (i.e., 
Table 2. $r^{2}$ and slope coefficient values for the relationships between percent cover of different functional groups as measured with the use of grid-point intercept (GPI) and line-point intercept (LPI) in 311-ha plots from six community types. Values are shown for two scenarios, one where LPI cover is calculated with the use of all canopy data (all hits) and the other where LPI cover is calculated with the use of only the uppermost canopy data (top hit only). The percent change in slope $(\% \Delta \beta)$ indicates the magnitude of change in $\beta$ when LPI cover is calculated two different ways. No trees were detected with the use of the LPI sampling technique.

\begin{tabular}{|c|c|c|c|c|c|}
\hline \multirow[b]{2}{*}{ Functional group } & \multicolumn{2}{|c|}{ GPI vs. LPI all hits } & \multicolumn{2}{|c|}{ GPI vs. LPI top hit only } & \multirow[b]{2}{*}{$\% \Delta \beta$} \\
\hline & $r^{2}$ & $\beta$ & $r^{2}$ & $\beta$ & \\
\hline Rock & 0.85 & 0.86 & 0.68 & 1.01 & 15 \\
\hline Soil & 0.01 & -0.05 & 0.88 & 0.87 & 92 \\
\hline Litter & 0.01 & 0.02 & 0.01 & 0.04 & 2 \\
\hline Coarse woody debris & 0.26 & 0.17 & 0.12 & 0.20 & 3 \\
\hline Annual grass & 0.94 & 0.91 & 0.95 & 1.01 & 10 \\
\hline Perennial grass & 0.90 & 0.51 & 0.94 & 0.83 & 32 \\
\hline Exotic forb & 0.95 & 0.50 & 0.96 & 0.70 & 20 \\
\hline Native forb & 0.90 & 0.52 & 0.81 & 0.70 & 18 \\
\hline Shrub & 0.92 & 0.88 & 0.92 & 0.91 & 3 \\
\hline
\end{tabular}

31 pairs of plots), where each pair represented one physical location where vegetation was quantified in two different ways. We generated a NMS ordination biplot with the use of percent cover of functional groups for each plot pair. Plots nearer each other in ordination space had more similar plant communities. Consequently, if LPI and GPI represented the vegetation of a given plot identically, the two ordination biplot points for that plot (i.e., one for GPI and one for LPI) would overlap in ordination space. NMS analyses were run with the use of methods described in Arkle et al. (2010).

Within-Plot Subsampling. We assessed subsampling adequacy to evaluate how well three transects, 36 GPI quadrats, and nine PQ sampling points characterized vegetation in 1-ha plots. For each sampling method, functional group, and plot, we plotted the relative standard error ( $\mathrm{RSE}=\mathrm{SE} /$ mean) of percent cover estimates against the mean percent cover estimate for the plot. Logarithmic functions were fitted to these data. We expected that RSE should decrease as the estimate of percent cover increases for a particular functional group. Based on this expectation, the appropriate number of within-plot subsamples should not be constant, but should instead depend on the total percent cover of the functional group and on its distribution within the plot. RSE values greater than $20 \%$ are generally considered high for ecological studies (McCune and Grace 2002) and indicate high spatial heterogeneity or inadequate within-plot subsampling. Therefore, with the use of the full number of within-plot subsamples for each sampling method ( $n=$ three LPI transects, 36 GPI quadrats, and nine PQ samples per plot), we determined percent cover values of different functional groups where RSE was $\leq 20 \%$.

We also examined within-plot subsampling adequacy at the community level. We evaluated only the GPI method with the use of this approach because the LPI method had too few within-plot subsamples and the PQ method only generated percent cover estimates for 3 of the 10 possible functional groups within each plot. With the use of PC-ORD 5.10 software (McCune and Medford 2006), distance-area (or distance-effort) curves were generated separately for each plot to determine the minimum number of GPI quadrats required to represent the entire vegetation community of the plot. This method is analogous to the more familiar species-area (or species-effort) curve, except that it incorporates information on both species presence and abundance in each subsample (quadrat). For each plot, we took 500 bootstrap resamples (with replacement) of GPI quadrats at each possible number of subsamples (i.e., 1-35 quadrats). We then calculated the Sorenson distance between the vegetation community as represented by all 36 GPI quadrats and the vegetation community as represented by fewer (i.e., 1-35) of the 36 quadrats. When the average distance between a subset of GPI quadrats and the entire population of 36 GPI quadrats is small (e.g., <10\%, McCune and Grace 2002), the lower number (subset) of quadrats is effectively representing the vegetation community in the plot, regardless of which particular quadrats are included. For each plot, we determined the number of GPI quadrats, which resulted in an average Sorenson distance of $<10 \%$ from the entire population of 36 GPI quadrats. This number of GPI quadrats per plot was averaged by community type. We repeated these analyses first with the use of specieslevel and then functional group-level cover data with and without abiotic habitat components (e.g., litter, soil) because we suspected that the amount of within-plot replication required to represent vegetation communities might depend on the taxonomic resolution of the plant community and on the inclusion of common abiotic components (e.g., litter or soil).

Effort Requirements. Effort requirements for all three methods were evaluated on the basis of time required for a crew, trained in sampling methods and vegetation identification, to set up and complete sampling (including photographic analysis time for GPI) for each plot. We calculated the number of personhours used on each plot per subsample and per measurement point (pin drop for LPI and pixel for GPI). Values were averaged by community type and across all plots.

For the LPI method, we examined the amount of information gained through the additional sampling effort of recording understory species. We determined the probability of lower canopy (i.e., understory) plants contacting the pin flag in each plot and averaged these values across community types. This analysis also gives an indication of the amount of plant-cover information lost through nadir sampling approaches like photography-based GPI.

\section{RESULTS}

\section{Quantifying Percent Cover}

Point-Intercept Methods. We generated percent cover estimates in 1-ha plots for 52 plant species with the use of the LPI sampling method and 64 species with the use of the GPI method across all plant communities. We found that percent cover values obtained with the use of LPI and GPI were significantly correlated for most functional groups at the plot level (Table 2). There was no significant effect of community type on the relationship between percent cover values derived from LPI and GPI. Therefore, in subsequent regression 

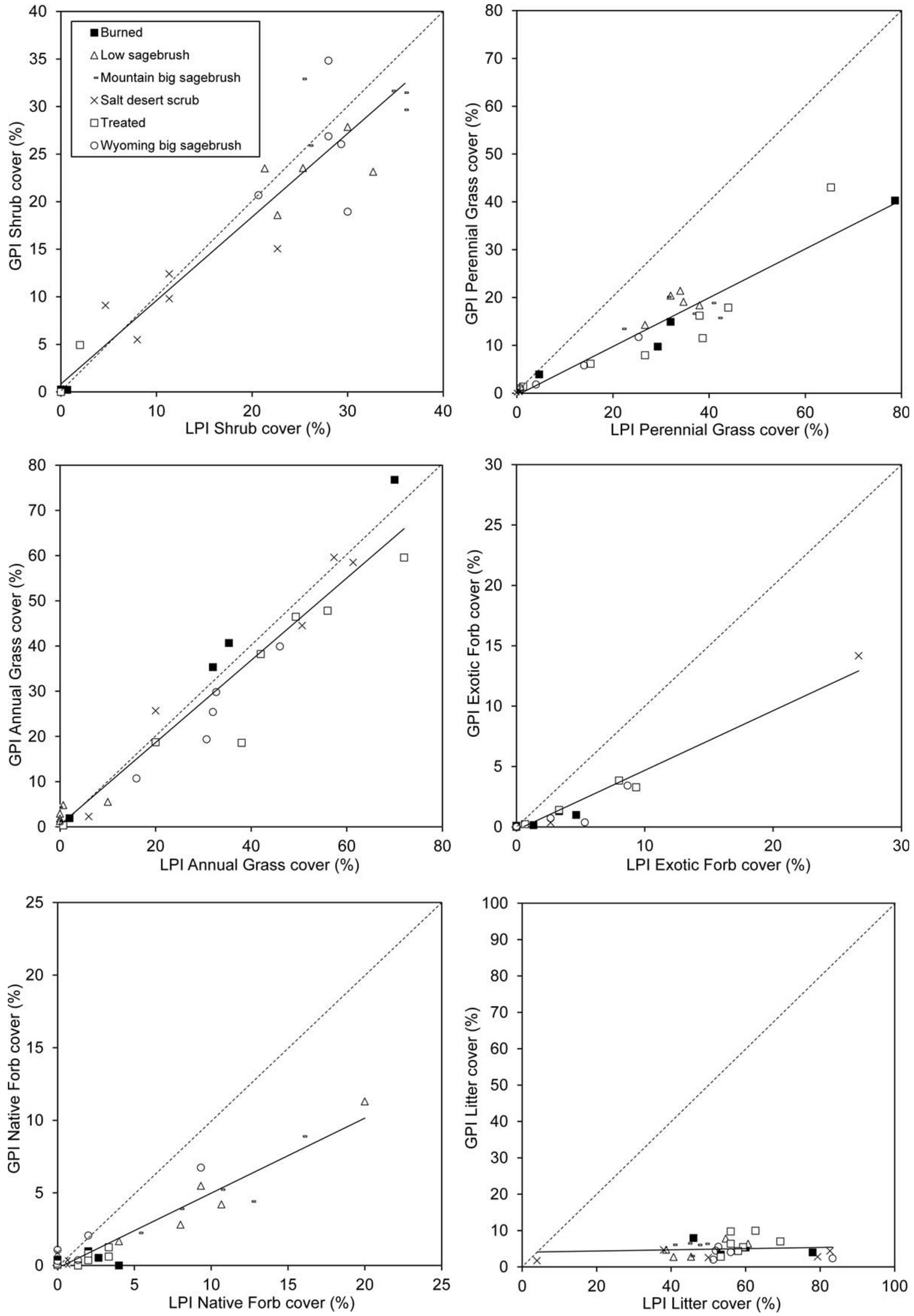

Figure 2. Percent cover of six functional groups measured in 1-ha plots $(n=31)$ with the use of grid-point intercept (GPI) and line-point intercept (LPI) methods. Plots are symbolized by community type $(n=6)$. The solid line was fitted with the use of regression, and the dashed line represents a $1: 1$ relationship in cover values between methods $(\beta=1)$. Several functional groups are not shown, but are listed in Table 2 . See text for plant functional group and vegetation community type descriptions. 

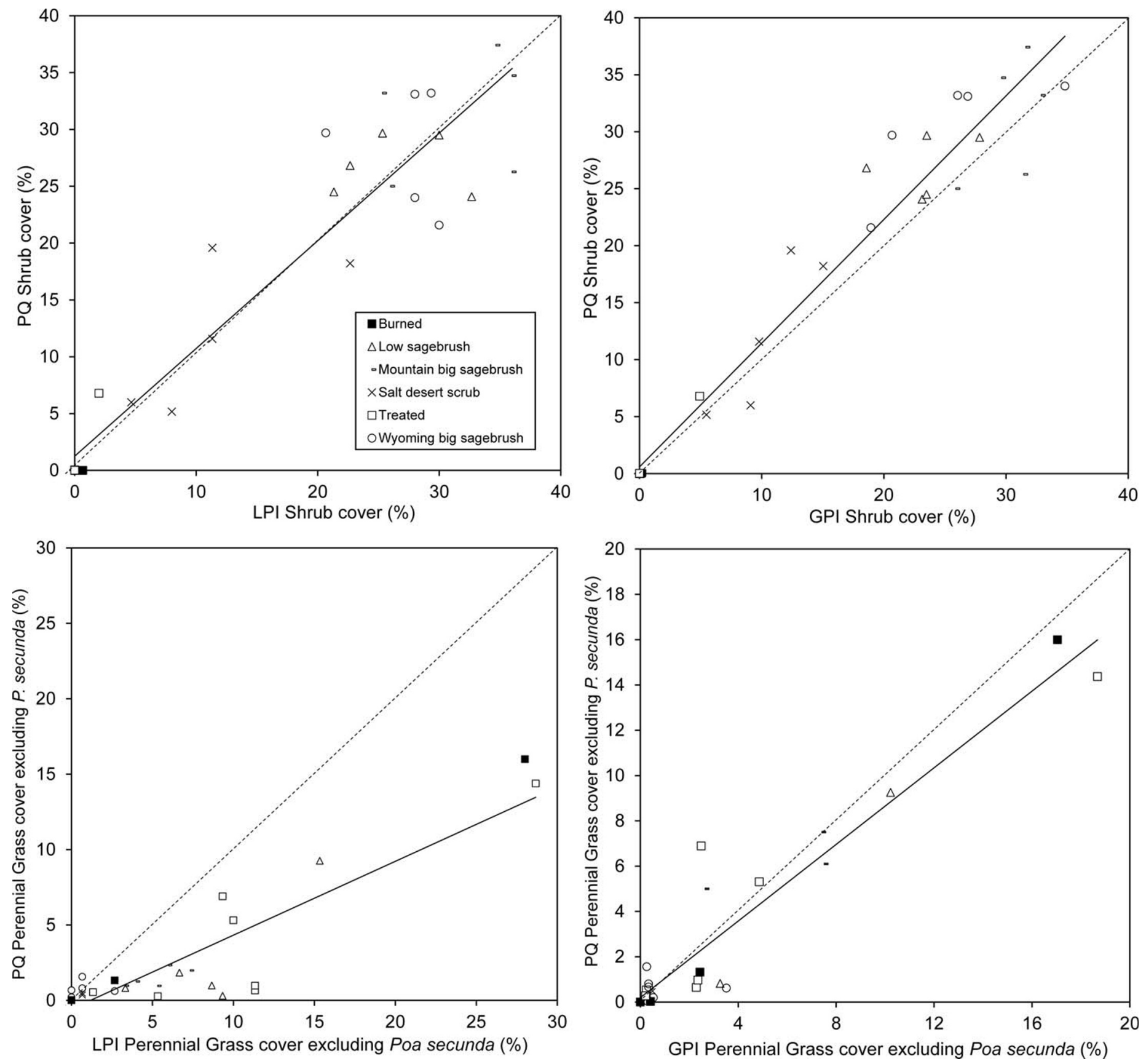

Figure 3. Percent cover of Shrub and Perennial Grass (excluding Poa secunda) functional groups measured in 1-ha plots ( $n=31$ ) with the use of pointcentered quarter (PQ) and line-point intercept (LPI) methods (left column), and PQ and grid-point intercept (GPI) methods (right column). Plots are symbolized by community type $(n=6)$. The solid line was fitted with the use of regression and the dashed line represents a 1:1 relationship in cover values between methods $(\beta=1)$. Tree functional group is not shown. See text for plant functional group and vegetation community type descriptions.

analyses, community type was not included as a cofactor. Shrub and Annual Grass functional group cover estimated from LPI were both strongly correlated with estimates from GPI, and values were nearly 1:1 between methods (Table 2). Percent cover values for Perennial Grass, Exotic Forb, and Native Forb functional groups also were strongly correlated, but cover values generated from GPI were substantially lower than those generated with the use of LPI (Table 2) even when these functional groups were the uppermost canopy present on the plot (e.g., Perennial Grass on Burned or on Treated plots; Fig. 2). Litter and Soil cover values generated with the use of the two methods were uncorrelated. GPI-derived Litter cover estimates showed little variability among plots $(0-10 \%$ litter cover for all plots; Fig. 2) and LPI-derived Soil cover estimates showed little variability among plots $(80-100 \%$ soil cover for all plots). Trees were not detected with the use of LPI (even when pin flags were projected upwards), but seedlings or branches that were lower than $2 \mathrm{~m}$ were determined to comprise up to $2.5 \%$ cover with GPI methods.

The correspondence between cover estimated from LPI and GPI methods improved when we used only the uppermost object contacting each pin flag (i.e., top hit) for LPI estimates 
Table 3. $r^{2}$ and slope coefficient values for the relationships between percent cover as measured with the use of the point-centered quarter method (PQ) and line-point intercept (LPI) or PQ and grid-point intercept (GPI). Values are shown for analyses where LPI all-hit and top-hit only data were used. No trees were detected with the use of the LPI sampling technique.

\begin{tabular}{lcccccccc}
\hline & \multicolumn{2}{c}{$\mathrm{PQ}$ vs. LPI all hits } & & \multicolumn{2}{c}{$\mathrm{PQ}$ vs. LPI top hit only } & & \multicolumn{2}{c}{$\mathrm{PQ}$ vs. GPI } \\
\cline { 2 - 3 } Functional group & $r^{2}$ & $\beta$ & & $r^{2}$ & $\beta$ & & $r^{2}$ & $\beta$ \\
\hline Perennial grass & 0.81 & 0.49 & & 0.79 & 0.80 & & 0.9 & 0.85 \\
Shrub & 0.90 & 0.95 & & 0.90 & 0.98 & & 0.95 & 1.08 \\
Tree & - & - & & - & - & & 0.65 & 0.43 \\
\hline
\end{tabular}

(Table 2). This improvement was observed primarily for lower canopy species.

PQ Method. PQ cover results were comparable to those of LPI and GPI across cover gradients and among plant communities. We detected nine perennial bunchgrass, 14 shrub, and two tree species across all plots with the use of the PQ method. In the same plots, we detected eight perennial bunchgrass, 12 shrub, and no tree species using the LPI method. Percent cover values obtained using PQ and LPI were strongly correlated (Fig. 3). For Shrubs, the $\beta$ value between LPI and PQ methods was nearly 1 (Table 3 ). For Perennial
Grass, however, the PQ estimate of cover was approximately half that of the LPI estimate $(\beta=0.49$; Table 3$)$. Lower cover derived from the PQ method was likely influenced by the methodological restriction that only bunchgrasses with canopy intercept $\geq 15 \mathrm{~cm}$ were included in PQ cover measurements. In contrast, we included bunchgrasses of any size when measuring Perennial Grass cover using the LPI method. The 1:1 correspondence between cover estimates generated from these two sampling methods improved ( $\beta$ closer to 1 ) when only LPI top-hit data were used to determine percent cover values (Table 3 ).

We detected the same bunchgrass, shrub, and tree species with the use of GPI as were detected with the use of PQ. Percent cover values obtained with the use of PQ and GPI were strongly correlated for Shrub and Perennial Grass (excluding Poa secunda cover) functional groups (Table 3 and Fig. 3 ) and $\beta$ values were close to 1 . Tree functional group cover was correlated between the two techniques $\left(r^{2}=0.65\right)$; however, the observed range of tree cover was limited to only $0-3 \%$. There was high variability in tree-cover estimates among GPI quadrats at plots where trees were detected ( $\mathrm{SE}=$ mean cover value in all seven plots). Standard error of tree cover estimates was less when PQ was used (SE $<100 \%$ of mean cover value in six of seven plots where trees were detected with the use of PQ).

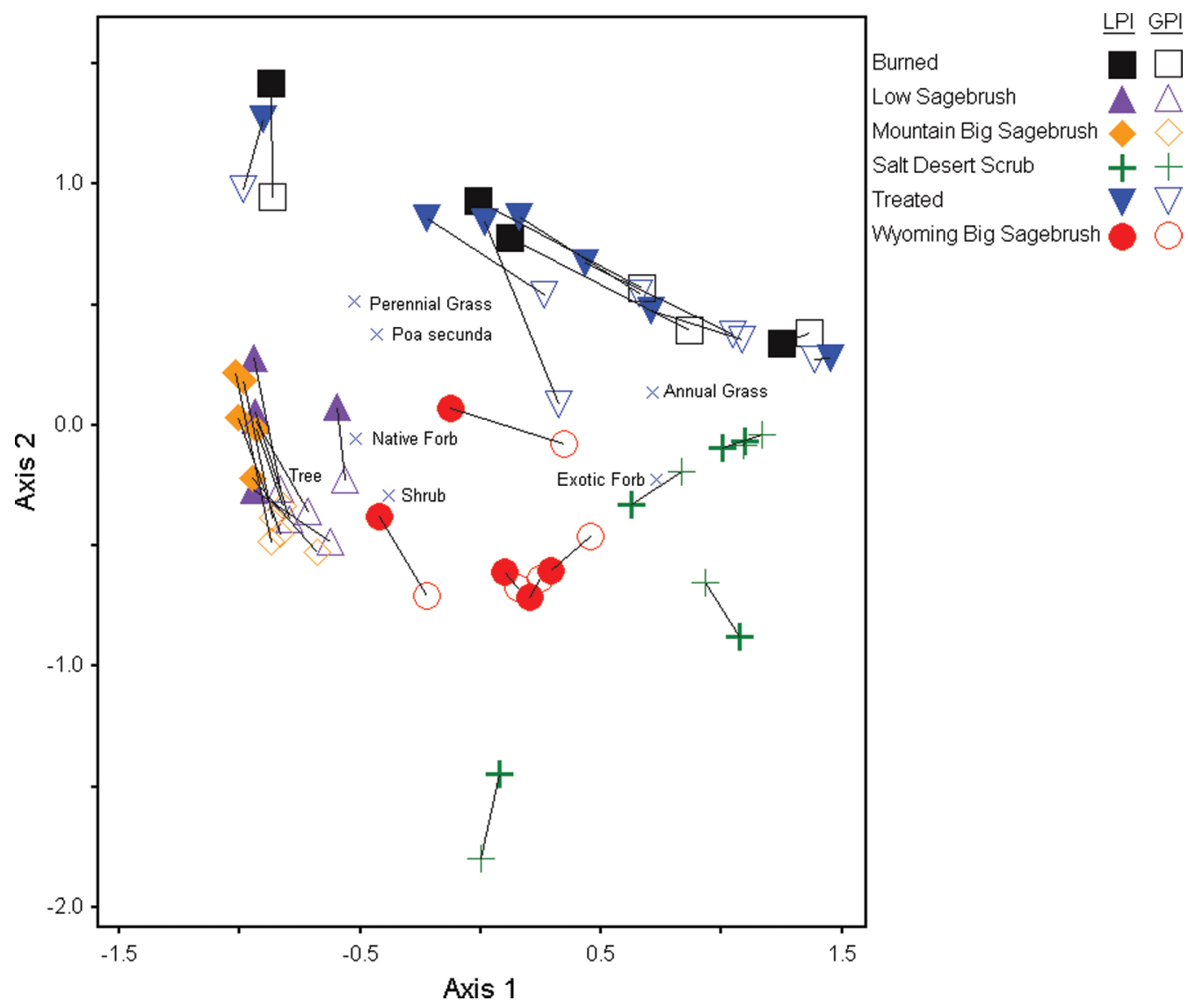

Figure 4. Nonmetric multidimensional scaling (NMS) ordination biplot of cover data for seven plant functional groups measured on the same 1-ha plots with the use of line-point intercept (LPI) (darker symbols) and grid-point intercept (GPI) (lighter symbols) sampling methods across six vegetation community types. See text for plant functional group and vegetation community type descriptions. 

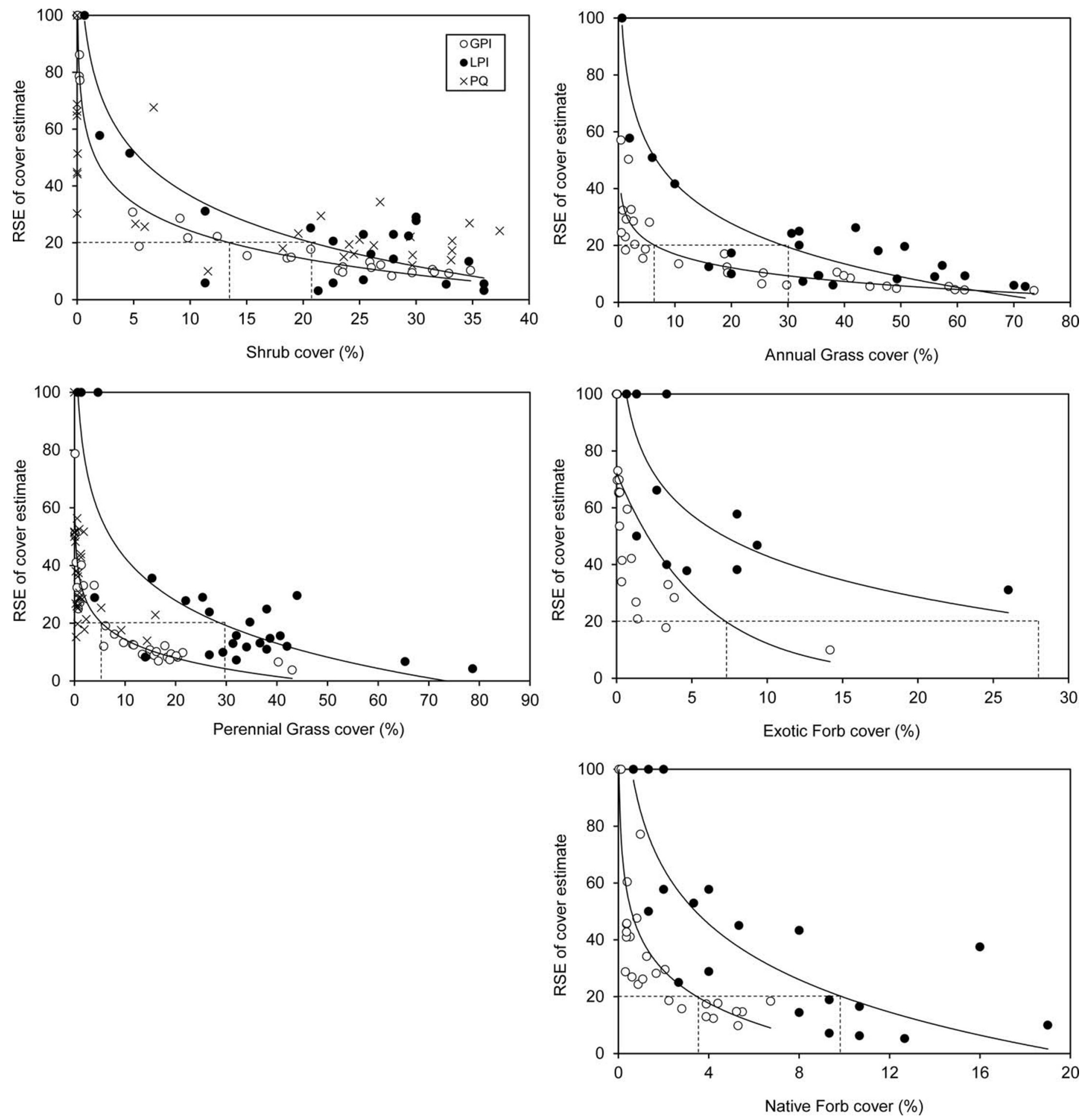

Figure 5. Relative standard error (RSE) of within-plot cover estimates versus mean within-plot percent cover estimates for five functional groups. All 31 1ha plots are shown for each sampling method. Within-plot replication used to derive RSE and mean percent cover estimates was 36 grid-point intercept (GPI) quadrats, three line-point intercept (LPI) transects, and nine point-centered quarter method (PQ) points. Solid lines are fitted curves for the GPI (upper) and LPI (lower) methods, and dashed lines indicate the percent cover estimate where RSE was $\leq 20 \%$ for GPI and LPI. These lines were not included for $P Q$ to increase clarity and because of high similarity to curves fitted for GPI estimates. Only Shrub and Perennial Grass cover are shown for the $P Q$ method.

\section{Community Composition}

NMS ordination of cover data for seven plant functional groups measured with LPI and GPI on the same 1-ha plots produced a two-axis solution (stress $=12.15, P=0.003$ ) repre- senting $92 \%$ of the variance in the original data. Axis 1 represented $58 \%$ of the variance in the original data and described a gradient of dominance from Annual Grass (increasingly positive Axis 1 values) to Native Forb, Shrub, 
Table 4. With the $10 \%$ Sorenson distance used as a cutoff, the average number of within-plot grid-point intercept (GPI) quadrat subsamples necessary to represent the vegetation community (as represented by 36 quadrats) in 1-ha plots is shown. Values shown are the mean number of GPI quadrats from all plots $(n=4-7)$ per community type. Four separate analyses were run for each plot with the use of functional group-level and species-level cover data and including or excluding percent cover of abiotic habitat components (Litter, Coarse Woody Debris, Soil, Rock). Values in parentheses exclude one partly burned plot.

\begin{tabular}{lcccccc}
\hline & \multicolumn{2}{c}{ Functional } & groups & & \multicolumn{2}{c}{ Species } \\
\cline { 2 - 3 } \cline { 6 - 7 } \multicolumn{1}{c}{ Community type } & Biotic & Biotic and & & Species & Species and \\
ably & abiotic & & only & abiotic \\
\hline Burned & 6.5 & 5.5 & & 7 & 5.5 \\
Treated & 8 & 5.4 & & 9.3 & 6.1 \\
& $(6.7)$ & $(5.2)$ & & $(7.5)$ & $(5.8)$ \\
Salt desert scrub & 7.4 & 4.4 & & 13 & 6.2 \\
Wyoming big sagebrush & 7.2 & 6.4 & & 10.2 & 8.2 \\
Low sagebrush & 9.4 & 6.4 & & 14 & 8.8 \\
Mountain big sagebrush & 7.8 & 6.2 & & 14.4 & 10 \\
\hline
\end{tabular}

and Tree cover (increasingly negative Axis 1 values; Fig. 4). Axis 2 represented $34 \%$ of variance and was positively associated with cover of Perennial Grass and Poa secunda functional groups. Plot pairs, measured with the use of the two sampling methods, tended to separate along Axis 2. For most plots, community composition tended to be more associated with the Perennial Grass (including Poa secunda) functional group when measured with the use of LPI than when the community composition in the same plot was quantified with the use of GPI. In general, however, the two sampling methods produced similar representations of community composition.

\section{Within-Plot Subsampling}

Functional Group Level. The number of subsamples (i.e., LPI transects, GPI quadrats, PQ points) required to meet the RSE criterion (i.e., RSE <20\%) depended on functional group cover within each 1-ha plot (Fig. 5). The RSE of the percent cover estimate tended to be low when the percent cover of a particular functional group was high within a plot. As the cover of the functional group decreased within plots, RSE values increased toward $100 \%$. Community type did not have a significant influence on the relationship between RSE and mean cover estimates, and was therefore not included as cofactor in analyses. Logistic functions fit the observed data well, with $r^{2}$ values between 0.65 and 0.98 (Fig. 5).

We found that the mean percent cover of shrubs had to be greater than $21 \%$ for three LPI transects (number of subsamples per 1-ha plot) to have RSE values below the $20 \%$ threshold (Fig. 5). When LPI Shrub cover estimates were less than $21 \%$, the standard error was very high relative to the mean; we observed only five plots where shrub cover was greater than zero, but less than $21 \%$. In contrast to the LPI method, 36 GPI quadrats per 1-ha plot were insufficient when Shrub cover was $\leq 13 \%$. When GPI Shrub cover estimates were less than $13 \%$, the standard error was fairly low relative to the mean $(\mathrm{RSE}<30 \%$ when Shrub cover was between $5 \%$ and $10 \%$ ). We detected shrubs in 29 of 31 plots with the use the PQ method and thus only 2 PQ plots had values of zero in Figure 5 ( 8 plots had nonzero values that appear close to the $y$ axis). Relative to the other methods, PQ estimates of Shrub cover had lower RSE values at the low end of the range of cover values. PQ did not perform as well as the other methods when Shrub cover was $>20 \%$.

A similar pattern was observed for Perennial Grass, Annual Grass, Exotic Forb, and Native Forb cover. Thirty-six GPI quadrats per 1-ha plot were sufficient for RSE to be less than the $20 \%$ threshold when percent cover estimates were in the $4-$ $7 \%$ range (depending on the functional group). Percent cover estimates from LPI had to be two-three times greater than GPIderived estimates for RSE values $<20 \%$ (Fig. 5). For example, three LPI transects were insufficient to generate RSE values $<20 \%$ when Annual Grass or Perennial Grass cover were $\leq 30 \%$. When Perennial Grass cover was estimated with the use of the PQ method, RSE values were comparable to those generated by GPI and lower than values from LPI. RSE values from PQ were lower than GPI values when Perennial Grass cover was $<5 \%$, further demonstrating the utility of PQ when target species or functional groups are rare (Fig. 5).

Community Level. Distance-area curves generated for each plot (for example, Fig. S3; available at http://dx.doi.org/10. 2111/REM-D-13-00063.s3) indicate that the minimum number of GPI quadrats required to represent the composition and abundance of the vegetation in each plot varies with community type and with the desired taxonomic resolution (Table 4). The mean number of GPI quadrats needed to represent the community with functional groups (with both biotic and abiotic variables) was 5.8, whereas 11.7 quadrats were required to represent the community with species (without abiotic habitat cover included). In general, plots in higher elevation and more complex communities required more subsamples to meet the $10 \%$ reference level (Table 4 ).

Use of species-level percent cover data required two-five more subsamples than were required when functional grouplevel cover data were used. Including percent cover data on abiotic habitat components decreased the number of samples required by two-four GPI quadrats per plot (Table 4).

\section{Effort Requirements}

Regardless of the community type, the average amount of field time required for two-person teams to sample a single 1-ha plot was $1 \mathrm{~h}$ and $25 \mathrm{~min}$ for LPI (three 50-m transects), $1 \mathrm{~h}$ and 15 min for GPI (36 quadrats), and $1 \mathrm{~h}$ and $20 \mathrm{~min}$ for PQ (9 points). These estimates included time required for setup and time required for collecting ancillary data on plant height, species checklists, and plot information. After factoring in additional time requirements for photographic analysis (GPI required $5 \mathrm{~min}$ per image [3 s per pixel] on average) and additional personnel requirements (LPI is more efficient with two people-one data reader and one recorder-but field technicians can work independently when using the other two methods), we found that 6.7 GPI quadrats can be acquired for every LPI transect (Fig. S4, available at http://dx.doi.org/10. 2111/REM-D-13-00063.s4). Therefore, 20-25 GPI quadrats per 1-ha plot represented equal effort (in terms of personhours) to collecting the standard three LPI transect lines per 1- 


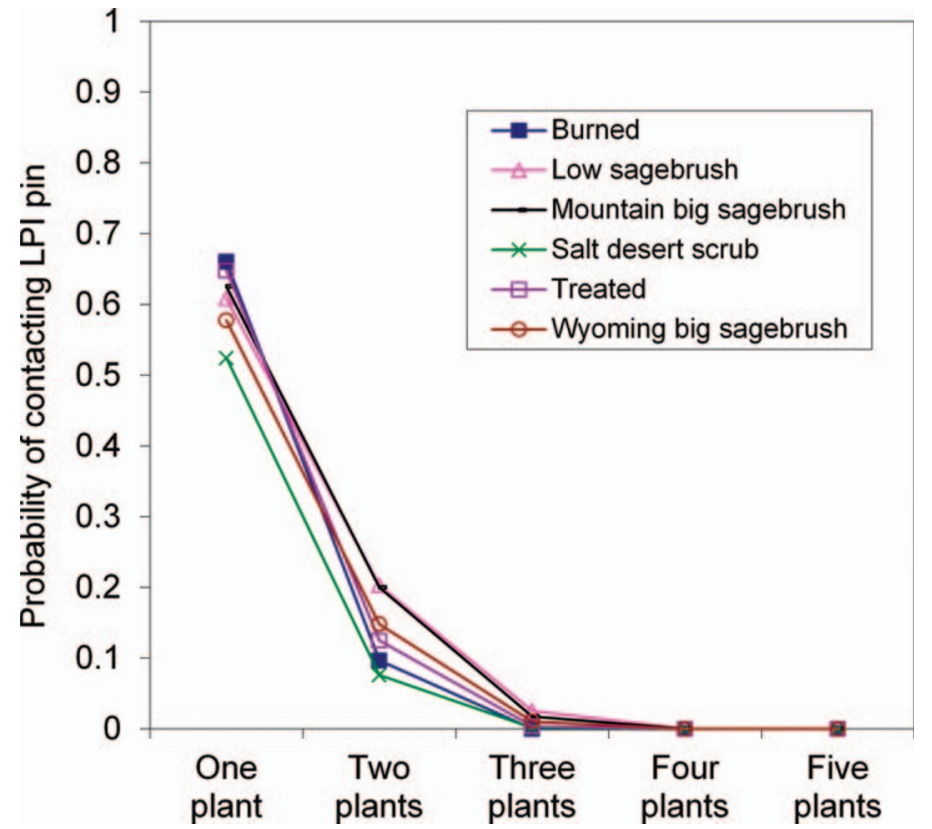

Figure 6. For each community type, the average probability of a line-point intercept (LPI) pin contacting one or more plant species. Estimates were based on 150 pin drops per 1-ha plot and probabilities from each plot were averaged by community type ( $n=4-7$ plots in six community types). Thus estimates were derived from 600, 750, and 1050 total pin drops in communities where four, five, or seven plots were sampled, respectively. Error bars were omitted for clarity, but SE values for the "One plant" column ranged from a low of \pm 0.06 for Salt Desert Scrub to a high of \pm 0.022 for Mountain Big Sagebrush. See text for plant functional group and vegetation community type descriptions.

ha plot. Approximately 10 PQ points per 1-ha plot equals the number of person-hours required to complete three LPI transects.

Based on a total of 2400 LPI pin drops, the probability of contacting one plant species was $0.52-0.66$, depending on community type (Fig. 6). Across all community types only $60 \%$ of pin drops contacted any plants; the other $40 \%$ contacted only abiotic functional groups. The probability of a pin flag contacting more than one species dropped sharply, with less than $1 \%$ of pins contacting three different species (Fig. 6). The probability of contacting one or two plant species was higher in community types with increasing elevation and precipitation, except for the Burned and Treated community types, which had the highest probabilities of observing one plant, but intermediate probabilities of detecting two plant species.

For most biotic functional groups, there was high agreement in percent cover estimates derived from LPI "top-hit only" data and LPI "all hit" data (Table 5). The relationship was strongest for Shrub and Annual Grass functional groups. Abiotic functional groups were either not correlated, or had relatively low $r^{2}$ and $\beta$ values. This was the same trend as was observed in the relationship between GPI and LPI top-hit only cover estimates (Table 2). Using LPI top-hit only data reduced species richness by an average of 0.39 species per transect line, with a maximum reduction of two species in any transect. However, at the plot level we found no net loss of species richness in any of the 31 plots.
Table 5. $r^{2}$-squared and slope coefficient values for the relationships between percent cover as measured with the use of line-point intercept (LPI) top-hit and LPI all-hit data. No trees were detected with the use of the LPI sampling technique.

\begin{tabular}{lcc}
\hline Functional group & $r^{2}$ & $\beta$ \\
\hline Rock & 0.95 & 0.63 \\
Soil & 0.01 & 0.06 \\
Litter & 0.17 & 0.14 \\
Coarse woody debris & 0.68 & 0.46 \\
Annual grass & 0.98 & 0.89 \\
Perennial grass & 0.94 & 0.78 \\
Exotic forb & 0.98 & 0.71 \\
Native forb & 0.96 & 0.68 \\
Shrub & 0.99 & 0.96 \\
\hline
\end{tabular}

\section{DISCUSSION}

All three methods performed well in characterizing shrubland and grassland vegetation in these northern Great Basin plant communities. Some aspects of their performance were influenced by environmental or vegetation conditions.

\section{Cover Estimates Across Vegetation Gradients}

The comparability or interchangeability of cover estimates derived from different methods is important for our purposes because it is a means of assessing relative accuracy (i.e., closeness to "truth") when true cover values within plots are unknown. From a broader perspective, comparability among methods is important for researchers needing to use or convert data from different sources, or for compiling data to create meaningful regional assessments (Godinez-Alvarez et al. 2009).

Regardless of community type or vegetation cover, the LPI and GPI methods produced estimates of cover that were highly correlated for most biotic functional groups, a finding congruent with a similar study that investigated five plant communities in the Chihuahuan Desert (Godinez-Alvarez et al. 2009). In particular, the two methods produced nearly equivalent $(\beta \approx 1)$ shrub cover estimates, which is encouraging given the recent emphasis on monitoring shrub cover for wildlife such as greater sage grouse (Centrocercus urophasianus). Also, it demonstrates that within the community types examined, photography-based GPI does not overestimate cover relative to LPI when tall (e.g., sagebrush or bitterbrush) plants are prevalent because of issues associated with parallax. Cover estimates for another important functional group, exotic annual grasses (mostly cheatgrass, Bromus tectorum), were also comparable between LPI and GPI.

The GPI method tended to underestimate bunchgrasses and forbs relative to LPI, which is partly a methodological artifact; LPI provides multicanopy data, whereas GPI provides information on only the uppermost plant at any given point. This is supported by our finding that top-hit data from LPI resulted in increased agreement in cover estimates between LPI and GPI. This is not the only explanation, though, as LPI still tended to overestimate bunchgrass, native forb, and exotic forb cover relative to GPI, even in Burned and Treated community types where these plants were always the uppermost canopy of plots. 
We suspect there may also be some observer bias associated with LPI because field personnel decide whether a plant is contacting a pin flag when it is close to the pin, an issue that is complicated by the movement of flexible plants in even light winds (Cagney et al. 2011). Further, the pixel size in our photography-based GPI was about half the diameter of the pin used by field crews, depending on the distance of the plant to the lens. Finally, even slight deviations from vertical when holding a pin flag greatly increase the plant-pin contact area. Collectively, these factors may increase the number of LPI points contacting vegetation relative to photography-based GPI points (Booth et al. 2005). With 50 sampling points per LPI transect, each additional sampling point where a given species contacts a pin flag results in a $2 \%$ increase in the cover estimate for that species.

We found that across community types, PQ and GPI resulted in similar estimates of shrub and bunchgrass (excluding Poa secunda) cover. This was surprising given that there are substantial differences between these two techniques, including an area-based versus plotless approach, and a size requirement for PQ where shrubs and bunchgrasses smaller than 10-15 cm diameter were excluded. However, excluding Poa secunda from GPI cover estimates for this particular analysis meant that predominantly larger individuals (e.g., $>15 \mathrm{~cm}$ diameter) were included in GPI cover estimates and it was these larger individuals that were targeted using the PQ method. For shrubs, individuals $<10 \mathrm{~cm}$ in diameter contributed little to the total plot area covered by shrubs. Consequently, excluding smaller individuals had little effect on PQ estimates.

PQ and LPI cover estimates were also well correlated and nearly 1:1 for shrubs. However, for bunchgrasses, PQ underestimated cover relative to LPI. Although, as with GPI, correspondence improved when LPI top-hit only data were used. However, LPI still produced slightly higher cover estimates than PQ even after applying this correction (possibly for reasons similar to those discussed above).

\section{Precision of Cover Estimates Across Vegetation Gradients}

Successfully quantifying vegetation and detecting change in heterogeneous shrublands depends on reasonably precise measurements of cover (e.g., Havstad and Herrick 2003). We found that regardless of community type, the precision of cover estimates across 1-ha plots was highly dependent on the abundance (i.e., cover) of the species or functional group being measured. When cover values within plots were low, precision was low and methodological approach (e.g., LPI, GPI, PQ), number of subsamples (i.e., number of line transects, quadrats, PQ points), and vegetation characteristics (i.e., community type, within-plot patchiness) had comparatively small influences on precision. Precise estimates of cover are critical for detecting small changes in vegetation cover through time and providing a level of confidence on cover estimates. For example, this precision may be important for management decisions regarding wildlife and range health.

The GPI method produced fairly precise estimates of cover across the range of cover values and vegetation communities. Photography-based GPI has been shown to produce precise estimates of cover (Booth et al. 2006a; Seefeldt and Booth 2006), although our results show that this precision is dependent on the cover of target species or functional groups. Sample sizes of six-nine GPI quadrats per hectare adequately characterized these vegetation communities, but when cover values were below $5-10 \%$, even 36 GPI quadrats per hectare was insufficient to estimate cover precisely for most functional groups. Inouye (2002) found that species with average cover less than $5 \%$ required more than 50 GPI quadrats $(0.5 \times 1.0 \mathrm{~m}$ frames) to achieve adequate precision in a 1.4-ha study plot that was dominated by Wyoming big sagebrush.

Depending on the functional group, LPI cover estimates had to exceed $10-30 \%$ cover and GPI cover estimates had to exceed $5-13 \%$ cover to be estimated precisely. LPI measurements of cover are fairly unbiased relative to other estimators (Elzinga et al. 2001), except when target objects are rare (Stohlgren et al. 1998). Methodological tests have found that it can take about 2000 points to estimate the cover of species with $<8 \%$ cover within $10 \%$ of the mean with $95 \%$ confidence (Walker 1970). Our 150 LPI points per plot is only $7.5 \%$ of this recommended criteria. Our photography-based GPI resulted in 3600 points per 1-ha plot (100 points within each of $363-\mathrm{m}^{2}$ quadrats), an amount that could still be considered insufficient at low cover values. Clearly, when target species or functional groups are rare, or as vegetation heterogeneity increases, some adaptation of methods may be necessary, such as increasing the number of points per subsample (i.e., more transect lines or quadrats) or number of subsamples per plot (Fisser and VanDyne 1966; Floyd and Anderson 1987; Brady et al. 1995; Inouye 2002). At cover values less than $10 \%$, the PQ estimates produced comparatively low relative standard error values, indicating that this method is well suited for measuring cover of sparse plants and could be used to supplement other methods when cover values of target species or functional groups are low.

At the community level (i.e., all functional groups considered together), we found that the average number of within-plot GPI quadrats necessary to represent plot conditions depended on community type and on whether species or functional groups were analyzed. When biotic and abiotic functional groups were analyzed together to represent plot conditions, approximately six GPI quadrats were needed regardless of community type. However, when species were analyzed without abiotic habitat components, 7-14 GPI quadrats were needed, with this value depending more strongly on community type. Low Sagebrush and Mountain Big Sagebrush communities, which occur at higher elevations, required more subsamples than Wyoming Big Sagebrush or Salt Desert Scrub communities. Grasslands (i.e., Burned community type) and seeded areas formed by recent wildfire and restoration activities (i.e., Treated community type) had simple vegetation composition and structure and required less subsampling and sample replication than the other habitat types.

\section{Representing Community Composition}

Across a broad range of successional and invasive plant dominance conditions, GPI and LPI sampling methods produced very similar representations of community composition. For example, in three of five Salt Desert Scrub plots, community composition was nearly indistinguishable between the two methods. Both sampling methods also indicated that Mountain Big Sagebrush and Low Sagebrush plant communi- 
ties were similar to one another at the functional group level, although GPI yielded slightly better separation of these two communities. PQ was not used for measuring community composition.

In preliminary analyses, we found that community-level ordinations with abiotic functional groups included resulted in poor agreement between the two methods. This was because 93\% of LPI points contacted Soil and 59\% contacted Litter, whereas these functional groups were far less common in the GPI data (38\% and $5 \%$ cover on average, respectively). Thus, differences among biotic functional groups were trivialized by differences among abiotic functional groups. Use of LPI top-hit only data, instead of multiple-canopy data, improved agreement between the two methods.

Point-based methods, such as LPI and GPI, have been considered inadequate to monitor biological diversity because they often fail to detect rare species (Stohlgren et al. 1998). Although we found similar species assemblages with the use of the three methods, we did not assess the effectiveness of these methods for detecting rare species. This is usually better accomplished through visual surveys. However, we found that PQ was adept at detecting and providing percent cover estimates for sparse plants, potentially making this method useful for research or monitoring programs involving lowabundance target species. Similarly, an added feature of the GPI method is the ability to search each quadrat area for species occurrence visually, which can be summed across the subsamples in a given plot to provide frequency estimates when cover is low within quadrats.

\section{Efficiency of Vegetation Sampling}

In agreement with past studies, the GPI method produced a relatively high number of subsamples per unit effort (e.g., Brun and Box 1963; Booth et al. 2005). Booth et al. (2005) found high efficiency even when image processing time was included in calculations. This efficiency may be particularly important when vegetation is spatially heterogeneous because larger sample sizes (i.e., more plots and within-plot subsamples) are required for adequate precision of cover and species richness estimates. After adjusting for photograph analysis time, we found that 20-25 GPI quadrats per hectare represented equal effort, in terms of person-hours, to collecting data in 1-m intervals on three 50-m LPI transects per plot. However, distance-ordination curves suggest that as few as six GPI quadrats may be needed in some vegetation communities. Approximately $10 \mathrm{PQ}$ points per hectare represents equal effort to three LPI transects per plot, but we also found that reducing PQ points from nine to six points per plot changed PQ cover estimates by less than $1 \%$ on average. Thus fewer PQ points may be sufficient to estimate cover across 1-ha plots in most community types. The efficiency of PQ and GPI is due to two factors. First, they require no transect or plot setup. Field technicians can simply navigate to sampling locations and begin data collection. Second, these methods enable field personnel to work independently instead of in pairs.

One potential limitation of the photography-based GPI approach is that it only captures information on the uppermost canopy. This may be particularly problematic for obtaining structural habitat information (e.g., for wildlife) in late- successional, multicanopied shrublands. However, we found that 100 points per photograph provided reasonable information on lower canopy layers (e.g., bunchgrasses, annual grasses, forbs, and rock, but not litter, down wood, or soil). Further, we found that only $8-20 \%$ of LPI points contacted more than one plant species, depending on community type. Thus, the majority of information (both in terms of cover and composition) is captured by the top hit in LPI. This has important implications for the use of LPI data as field validation of remote sensing imagery.

\section{IMPLICATIONS}

The three methods evaluated provided reasonable characterizations of shrubland plant communities and their use may depend on the objectives of the sampling. We confirm the precision of cover estimates generated by LPI, a standard method in quantitative rangeland monitoring. Photographybased GPI and PQ are not commonly used in rangeland vegetation sampling and monitoring, but we found that they were efficient field methods that could allow for increased spatial coverage within plots and perhaps allow for better characterization of vegetation or habitat heterogeneity across landscapes of interest. Photography-based GPI also offers future flexibility where existing archived images can be reanalyzed to address new objectives. We emphasize the importance of considering the limitations of each of these methods, especially factors that influence precision, such as low abundance or cover of target species or functional groups. Under this condition, we found that the PQ method performed best and could easily be added to supplement the other two methods. Use of robust and appropriate vegetation sampling methods should improve understanding and stewardship of rangelands through adaptive management. This information is timely as federal agencies in the western United States begin to implement quantitative estimates of cover and composition for rangeland monitoring with the goal of producing defensible assessments of rangeland health and restoration effectiveness at multiple spatial scales (Herrick et al. 2010, 2012).

\section{ACKNOWLEDGMENTS}

We thank the field assistants who helped collect these data. David Pyke and Troy Wirth (US Geological Survey) provided LPI data for plots in Oregon. Troy Wirth and anonymous reviewers provided helpful comments on an earlier version of this manuscript. Any use of trade names is for descriptive purposes only and does not imply endorsement by the US government.

\section{LITERATURE CITED}

Allcock, K., R. Nowak, B. Blank, T. Jones, T. Monaco, J. Chambers, R. Tausch, P. Doescher, V. Saytal, J. Tanaka, D. Ogle, L. St. John, M. Pellent, D. Pyke, E. Schupp, AND C. CALL. 2006. Integrating weed management and restoration on Western rangelands. Ecological Restoration 24:199.

Arkle, R. S., D. S. Pillod, and K. Strickler. 2010. Fire, flow and dynamic equilibrium in stream macroinvertebrate communities. Freshwater Biology 55:299-314.

Booth, D. T., S. E. Cox, and R. D. Berryman. 2006a. Point sampling digital imagery with 'SamplePoint.' Environmental Monitoring and Assessment 123:97-108. 
Booth, D. T., S. E. Cox, C. Fifeled, M. Phillips, and N. Willamson. 2005. Image analysis compared with other methods of measuring ground cover. Arid Land Research and Management 19:91-100.

Booth, D. T., S. E. Cox, M. Louhaich, And D. E. Johnson. 2004. Lightweight camera stand for close-to-earth remote sensing. Journal of Range Management 57:675678.

Booth, D. T., S. E. Cox, T. W. Meikle, and C. Fitzgerald. 2006b. The accuracy of ground-cover measurements. Rangeland Ecology \& Management 59:179-188.

Brady, W. W., J. E. Mitchell, C. D. Bonham, and J. W. Cook. 1995. Assessing the power of the point-line transect to monitor changes in basal plant cover. Journal of Range Management 48:187-190.

Briske, D., D. FuHLendorf, and F. E. Smeins. 2005. State-and-transition models, thresholds, and rangeland health: a synthesis of ecological concepts and perspectives. Rangeland Ecology \& Management 58:1-10.

BRUn, J. M., AND W. T. Box. 1963. Comparison of line intercepts and random point frames for sampling desert shrub vegetation. Journal of Range Management 16:21-25.

Cagney, J., S. E. Cox, And D. T. Booth. 2011. Comparison of point intercept and image analysis for monitoring rangeland transects. Rangeland Ecology \& Management 64:309-315

DaubenmiRe, R. F. 1959. A canopy-coverage method. Northwest Science 33:43-64.

Elzinga, C. L., D. W. Salzer, J. W. Willoughby, and J. P. GibBs. 2001. Monitoring plant and animal populations. Malden, MA, USA: Blackwell Science. $360 \mathrm{p}$.

Engeman, R. M., R. T. Sugihara, L. F. Pank, and W. E. Dusenberry. 1994. A comparison of plotless density estimators using Monte Carlo simulation. Ecology 75:17691779.

Epanchin-Niell, R., J. Englin, and D. Nalle. 2009. Investing in rangeland restoration in the arid west, USA: countering the effects of an invasive weed on the long-term fire cycle. Journal of Environmental Management 91:370-379.

FISSER, H. G., AND G. M. VANDYNE. 1966. Influence of number and spacing of points on accuracy and precision of basal cover estimates. Journal of Range Management 19:205-211.

Floyd, D. A., AND J. E. Anderson. 1982. A new point frame for estimating cover of vegetation. Vegetatio 50:185-186.

Floyd, D. A., AND J. E. Anderson. 1987. A comparison of three methods for estimating plant cover. Journal of Ecology 75:221-228.

Godinez-Alvarez, H., J. E. Herrick, M. Mattocks, D. Toledo, and J. Van Zee. 2009. Comparison of three vegetation monitoring methods: their relative utility for ecological assessment and monitoring. Ecological Indicators 9:1001-1008.

Hanley, T. A., 1978. A comparison of the line-interception and quadrat estimation methods of determining shrub canopy coverage. Journal of Range Management $31: 60-62$.
Havstad, K. M., and J. E. Herrick. 2003. Long-term ecological monitoring. Arid Land Research and Management 17:389-400.

Herrick, J. E., M. C. Duniway, D. A. Pyke, B. T. Bestelmeyer, S. A. Wills, J. R. Brown, J. W. KaRL, and K. M. Havstad. 2012. A holistic strategy for adaptive land management. Journal of Soil and Water Conservation 67:105A-113A.

Herrick, J. E., V. C. Lessard, K. E. Spaeth, P. L. Shaver, R. S. Dayton, D. A. Pyke, L. Jolley, AND J. J. Goebel. 2010. National ecosystem assessments supported by scientific and local knowledge. Frontiers in Ecology and Evolution 8:403-408.

Herrick, J. E., J. W. Van Zee, K. M. Havstad, and W. G. Whitford. 2005. Monitoring manual for grassland, shrubland and savanna ecosystems. Tucson, AZ, USA: University of Arizona Press. 236 p.

Huenneke, L. F., D. Clason, And E. Muldavin. 2001. Spatial heterogeneity in Chihuahuan Desert vegetation: implications for sampling methods in semi-arid ecosystems. Journal of Arid Environments 47:257-270.

INOUYE, R. 2002. Sampling effort and vegetative cover estimates in sagebrush steppe. Western North American Naturalist 62:360-364.

Knapp, P. A. 1996. Cheatgrass (Bromus tectorum L) dominance in the Great Basin Desert. Global Environmental Change 6:37-52.

McCune, B., And J. B. Grace. 2002. Analysis of ecological communities. Gleneden Beach, OR, USA: MjM Software. $304 \mathrm{p}$.

McCune, B., And M. J. MefFord. 2006. PC-ORD: multivariate analysis of ecological data. Version 5.10. Gleneden Beach, OR, USA: MjM Software.

Pehanec, J. F., and G. Stewart. 1940. Sagebrush-grass range sampling studies: size and structure of sampling unit. American Society of Agronomy Journal 32:669682.

Pehanec, J. F., and G. Stewart. 1941. Sagebrush-grass range sampling studies: variability of native vegetation and sampling error. American Society of Agronomy Journal 33:1057-1071.

Pyke, D. A., J. E. Herrick, P. Shaver, and M. Pellant. 2002. Rangeland health attributes and indicators for qualitative assessment. Journal of Range Management 55:584-597.

Seefeldt, S. S. and D. T. Booth. 2006. Measuring plant cover in sagebrush steppe rangelands: a comparison of methods. Environmental Management 37:703-711.

Stohlgren, T. J., K. A. BuLL, And Y. OtsuKI. 1998. Comparison of rangeland vegetation sampling techniques in the central grasslands. Journal of Range Management 51:164-172.

WALKER, B. H. 1970. An evaluation of eight methods of botanical analysis on grasslands in Rhodesia. Journal of Applied Ecology 7:403-416.

WiRTH, T. A., AND D. A. PYKE. 2007. Monitoring post-fire vegetation rehabilitation projects-a common approach for non-forested ecosystems. Corvallis, OR, USA: US Geological Survey Scientific Investigations Report 2006-5048. 36 p. 